\title{
PROCESSOS DA INDÚSTRIA QUÍMICA PARA ENGENHARIA DE PRODUÇÃO: DESAFIOS E EXPERIÊNCIAS EM ENSINO-APRENDIZAGEM INTERDISCIPLINAR
}

\author{
CHEMICAL INDUSTRY PROCESSES FOR PRODUCTION ENGINEERING: CHALLENGES
} AND EXPERIENCES IN INTERDISCIPLINARY TEACHING-LEARNING

Priscila Hasse Palharim ${ }^{1}$, Moisés Teles dos Santos ${ }^{2}$

DOI: 10.37702/REE2236-0158.v40p36-46.2021

\begin{abstract}
RESUMO
A indústria química é um setor que oferece oportunidades profissionais para diferentes especialidades de engenharia, incluindo Engenharia de Produção. Para que estudantes de Engenharia de Produção possam desempenhar atividades na área de processos químicos é necessário que possuam: i) um entendimento básico das principais operações comuns ao setor (operações unitárias); ii) a habilidade de realizar cálculos de eficiência e rendimentos econômicos e ambientais considerando os insumos materiais e energéticos usados nos processos para obtenção de produtos de valor econômico; e iii) um conhecimento básico das técnicas de avaliação econômica preliminar de projeto de processos químicos. Para que essas competências sejam adquiridas, o uso de balanços de massa e energia aplicados a processo é fundamental. $O$ presente trabalho apresenta a implementação de metodologias e ferramentas de ensino para se atingir esses objetivos educacionais em um curso de Processos Químicos ministrado a alunos de Engenharia de Produção pelo Departamento de Engenharia Química da Universidade de São Paulo (USP).
\end{abstract}

Palavras-chave: indústria química; Engenharia de Produção; Kahoot!; balanço de massa; balanço de energia; operações unitárias.

\begin{abstract}
The chemical industry is an industrial sector that offers several professional opportunities for different engineering specialties, including production engineering. To be able to work in chemical process, production engineering students must: i) have a basic knowledge of the main operations of this sector (unit operations); ii) have the ability to perform environmental and economic efficiency and yields taking into account the material and energetic resources used in the production of marketable products; iii) have the basic knowledge of preliminary economic evaluation of chemical processes. To get these skills, the use of mass and energy balances applied to chemical processes is fundamental. This work presents the implementation of several teaching methodologies and tools to meet this goal in a Chemical Process course for production engineering students offered by the Department of Chemical Engineering of University of São Paulo (USP).
\end{abstract}

Keywords: chemical industry; production engineering; Kahoot!; mass balance; energy balance; unit operations.

\footnotetext{
${ }^{1}$ Doutoranda, bolsista CAPES do Programa de Pós-Graduação em Engenharia Química da Escola Politécnica da USP, São Paulo-SP, ppalharim@usp.br

${ }^{2}$ Professor Doutor, Departamento de Engenharia Química da Escola Politécnica da USP, São Paulo-SP, moises.teles@usp.br 


\section{INTRODUÇÃO}

A indústria química representa um setor de grande expressividade econômica no Brasil e no mundo. Em 2018, o seu faturamento líquido foi de R\$ 450 bilhões em escala nacional e de US\$ 4.079 bilhões em escala mundial. No mesmo ano, a indústria química brasileira apresentou participação de $2,3 \%$ do PIB total (ABIQUIM, 2019). Os processos normalmente encontrados nas indústrias químicas são de tal forma diversificados que estas apresentam um campo de trabalho para diversas especializações da engenharia, tais como química, mecânica, de controle e automação e de produção.

Portanto, para que estudantes de Engenharia de Produção possam desempenhar atividades técnicas nas diferentes indústrias de processos químicos, é necessário que adquiram conhecimentos básicos que os permitam: i) entender os princípios básicos comuns a todas as operações industriais em uma escala macroscópica; ii) realizar cálculos de eficiência e rendimentos considerando os insumos materiais e energéticos dos processos necessários para obtenção de produtos de valor econômico; iii) ter um primeiro contato conceitual-descritivo das principais operações envolvidas nestas indústrias; e iv) conhecer metodologias básicas de avaliação econômica usadas em projetos preliminares de processos químicos.

Com base nesses objetivos, o presente trabalho relata o desenvolvimento e aplicação de atividades didáticas e a experiência obtida durante o curso de Processos Químicos (semestral e obrigatório) ministrado pelo Departamento de Engenharia Química da Escola Politécnica da USP para alunos de Engenharia de Produção da mesma instituição. O curso é baseado nos seguintes conteúdos programáticos típicos da Engenharia Química: balanços de massa, balanços de energia, operações unitárias e estimativa de custos de processos industriais químicos.

\section{METODOLOGIAS E FERRAMENTAS}

\section{Premissas básicas}

Como objetivo principal da disciplina, pretende-se que os conhecimentos adquiridos pelos alunos sirvam (direta ou indiretamente) para que estes sejam capazes de exercer atividades técnicas na indústria química, contribuindo ao projeto e operação de processos industriais que apresentem robustez econômica, que sejam ambientalmente corretos e que possam contribuir socialmente nas localidades em que estão inseridos, abrangendo assim os três pilares do desenvolvimento sustentável. A esses objetivos associamos o Nível 1 de objetivos pedagógicos.

Com as premissas estabelecidas no Nível 1, é necessário - sob a perspectiva do processo de produção industrial - habilitar os alunos a efetuarem cálculos de eficiências e rendimentos ambientais e econômicos. À habilidade de se efetuar tais cálculos associamos o Nivel 2 de objetivos pedagógicos. Esses cálculos são trabalhados em exercícios, provas e trabalhos dirigidos. Por fim, para que o aluno seja capaz de realizar tais cálculos, é necessário o entendimento dos princípios de conservação de massa e energia, aplicados nos diferentes processos, por meio dos balanços de massa e energia. Além disso, é necessário que o aluno entenda o propósito de diferentes operações usadas na indústria química (operações unitárias). A esse terceiro nível de objetivos (capacidade de realizar balanços de massa e energia e de se conhecer diferentes operações unitárias) associamos o Nível 3.

A Figura 1 representa uma associação entre os três níveis de objetivos destacados neste trabalho e a taxonomia de Bloom (ANDERSON et al., 2001). 
Figura 1 - Representação da taxonomia de Bloom e correspondência com níveis de objetivos instrucionais do curso

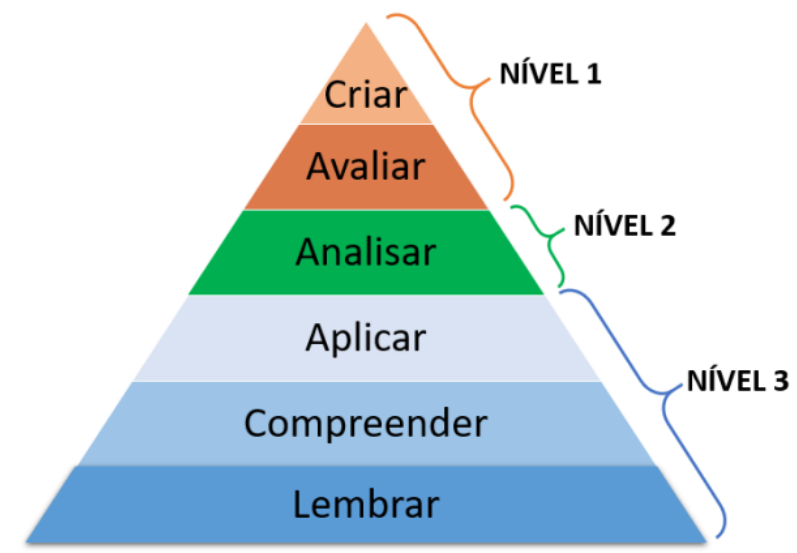

Fonte: elaborada pelos autores, 2020.

Nesta abordagem, procura-se valorizar dois aspectos que Teles dos Santos e Vianna Jr. (2018) indicam como benéficos no curso de engenharia: a ampliação do uso de ferramentas digitais para ensino e aprendizagem e a ênfase em competências numéricas e analíticas valorizadas pelo mercado de trabalho.

É importante destacar que todos os aspectos relacionados à natureza microscópica das operações das indústrias químicas estão fora do escopo da disciplina, pois exigem conhecimentos de termodinâmica, cinética de reações e fenômenos de transporte. Tais conhecimentos estão associados à formação em Engenharia Química e representam especificidades de conhecimentos que não estão alinhados aos objetivos do curso que é voltado para alunos de Engenharia de Produção. Embora evidente, esse aspecto é de grande importância pois impõe que temas abordados tradicionalmente em uma área (Engenharia Química) não podem simplesmente ser ministrados a alunos de outra formação (Engenharia de Produção) sem uma devida adaptação do escopo, das metodologias e dos exemplos (exercícios, trabalhos e avaliações).

\section{Estrutura do curso e avaliação}

O curso é semestral, totalizando 60 horas (4 créditos aula) e segue a seguinte estrutura básica:

- contexto e importância do curso;
- fluxogramas de processo, regime estacionário e transiente, variáveis de processo, unidades e conversão de unidades;

- balanço de massa sem reação em regime estacionário (1 unidade);

- balanço de massa sem reação em regime estacionário (várias unidades);

- balanço de massa sem reação em regime transiente;

- balanço de massa com reação em regime estacionário;

- balanço de energia (sistemas abertos e fechados) e utilidades;

- combustão I e combustão II;

- operações unitárias: trocadores de calor, destilação, absorção e extração;

- avaliação econômica.

Ao longo de todos os tópicos abordados, é dada ênfase à i) análise de graus de liberdade dos problemas, para que o aluno seja capaz de identificar se o problema pode ser resolvido com as informações disponíveis e por onde começar a resolução; ii) uso extensivo de exemplos industriais com várias unidades integradas e que incluam diversos segmentos industriais além do petroquímico (ex: produção de suco de laranja e de café solúvel, extração de óleos vegetais etc.); e iii) foco em questões relacionadas aos custos, qualidade $\mathrm{e}$ desempenho ambiental dos processos. São evitados exemplos e exercícios do tipo "um gás contido em um pistão..." que não possuem apelo de aplicação industrial para o aluno.

Os itens relacionados a balanços de energia, combustão e trocadores de calor são fortemente voltados para sistemas de utilidades industriais, produção e consumo de energia, envolvendo turbinas e caldeiras, de forma que o aluno seja exposto a problemas do tipo "Quantos $k W$ de energia são consumidos por $k g$ de produto no processo?" e "Qual a receita anual com a venda de energia elétrica excedente na fábrica?".

A avaliação é feita de três formas: i) duas provas escritas envolvendo cálculos; ii) trabalhos a serem entregues periodicamente (individuais e em grupo), também envolvendo cálculos; e iii) um seminário em que diferentes 
grupos apresentam um setor de atividade industrial química. Em relação ao seminário, é solicitado que os trabalhos abordem Aspectos Econômicos (com dados de volume de produção, preços, tendências e perspectivas, importância relativa na indústria etc.), Aspectos Ambientais (geração de efluentes, impactos do processo, aspectos energéticos) e Fluxograma básico do processo com as principais operações. Exemplos de setores trabalhados são Usina de Açúcar e Álcool, Produção de Celulose e Papel, Indústria de Fertilizantes, Petroquímica e Tratamento de Efluentes. Motivada pela pandemia da COVID-19, ocorreu ainda a inclusão dos setores de Produção de Álcool Gel e Produção de Oxigênio.

\section{Ferramentas de ensino}

\section{Uso do aplicativo Kahoot!}

Kahoot! é uma plataforma on-line que permite a criação de quizzes para aplicação em aula, utilizando-se apenas os celulares dos alunos (KAHOOT, 2012). A resolução interativa dos quizzes, baseada na pontuação e classificação final, gera competição benéfica entre os estudantes, além de proporcionar maior engajamento, motivação e concentração (WANG; TAHIR, 2020). Segundo Bawa (2018), a ferramenta com feedback em tempo real oferece revisão de conteúdos e informações sobre o nível de conhecimento dos estudantes.

\section{Videoaulas}

Após a passagem para o modo remoto, causada pela pandemia da COVID-19, as aulas foram ministradas de modo síncrono, por meio da plataforma Google Meet, gravadas e editadas com o software Active Presenter (ATOMI, 2020) e compartilhadas com os alunos a partir da plataforma Tidia.

\section{Plataforma Tidia}

O Tidia-Ae é um ambiente de aprendizado eletrônico que permite o gerenciamento de cursos, projetos e atividades de colaboração e de aprendizagem em grupo, oferecendo ferramentas de suporte à comunicação, distribuição de conteúdo, construção de conhecimentos e gerenciamento de participantes. O ambiente $A e$ é o resultado dos esforços do projeto Tidia-Ae, financiado pela FAPESP (Fundação de Amparo à Pesquisa do Estado de São Paulo), e associado ao IMS Global Learning Consortium e ao Sakai Foundation (TIDIA-AE, 2020). Esta plataforma foi usada durante o curso para compartilhamento de aulas (apresentações/ vídeos) e listas de exercícios, recebimento e gerenciamento de provas/trabalhos e divulgação de avisos.

\section{ESTUDO DE CASO}

Os conteúdos, ferramentas e metodologias apresentadas anteriormente foram usados na turma de 2020. Apenas três aulas foram ministradas presencialmente, devido ao isolamento imposto pela pandemia da COVID19. O curso é semestral, obrigatório e, especificamente nesse oferecimento, tinha um total de 98 matriculados.

\section{RESULTADOS}

A Figura 2 apresenta o resultado da avaliação dos alunos sobre o uso do aplicativo Kahoot! Nota-se que houve uma boa receptividade dos alunos com relação ao uso do aplicativo. Para o professor, uma grande utilidade da ferramenta é a identificação e correção (em tempo real) de erros conceituais cometidos pela turma. A possibilidade de revisão de conteúdos ainda mal assimilados por meio de cases, a correção em tempo real e o caráter dinâmico - por se tratar de uma atividade em que todos interagem - também foram aspectos positivos a se destacar. Um ponto de aperfeiçoamento na metodologia, segundo os alunos, seria disponibilizar as questões usadas para estudo depois do uso do aplicativo. A impossibilidade de voltar ao problema depois do uso do aplicativo foi uma reclamação recorrente. 
Figura 2 - Resultado da pesquisa sobre o uso do aplicativo Kahoot!

1. Você já tinha usado o Kahoot! antes?

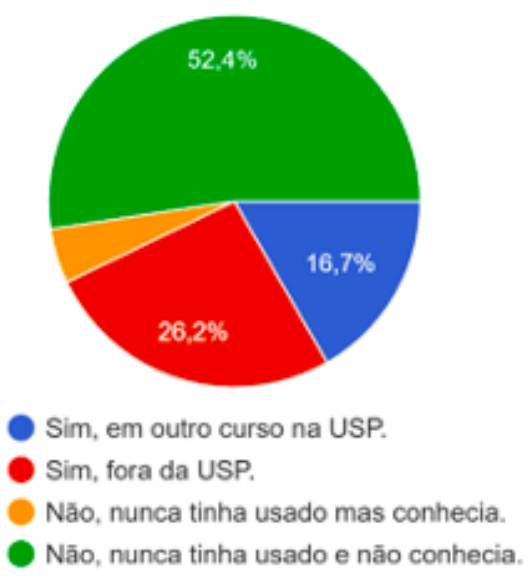

3. Em relação ao seu aprendizado em particular, assinale a alternativa que melhor representa o efeito do uso do Kahoot!:

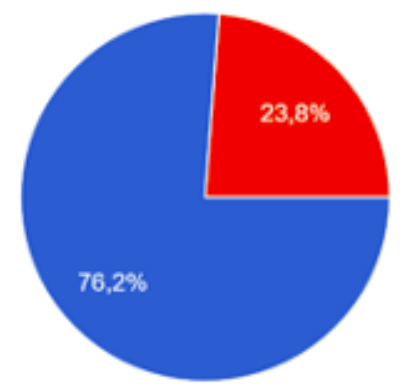

Melhorou meu aprendizado permitindo a revisăo de conteúdo e revelando conteúdos em que eu era deficiente.

Foi indiferente para o meu aprendizado.

Atrapalhou meu aprendizado.

5. Em relação à competição entre alunos estimulada pelo uso de pontos e "pódio" no Kahoot!, você acredita que:

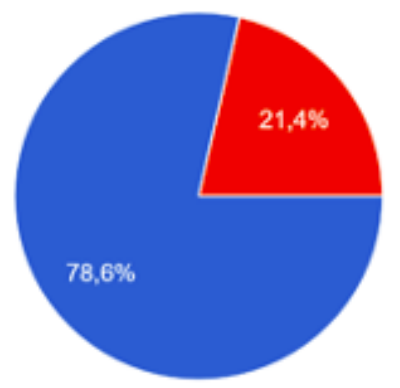

É adequada, pois competiçăo existe nos processos seletivos e no mundo real do mercado de trabalho.

É desnecessária, pois o ambiente de aprendizado não deve estimular competições.
2. Em relação ao aprendizado do conteúdo de forma geral, você acredita que o Kahoot!:

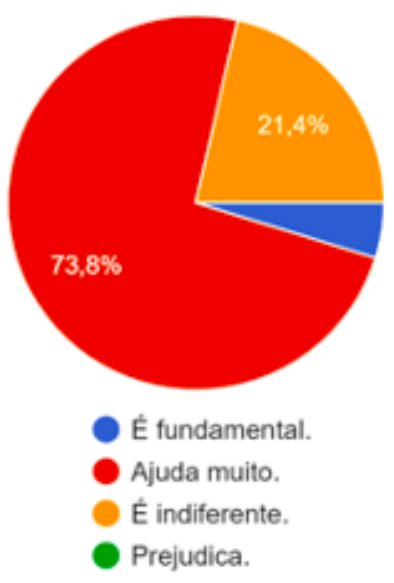

4. Na sua opinião, o tempo dado à resolução da maioria dos problemas foi:

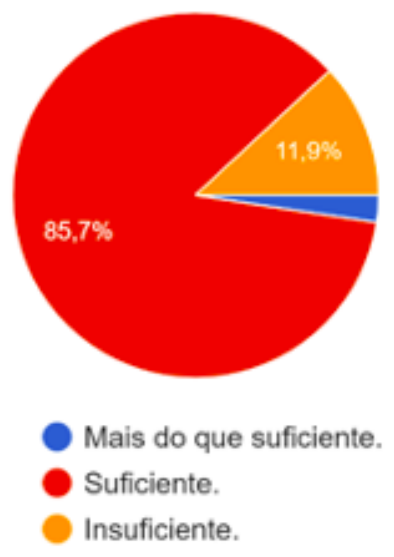

6. Na sua opinião, o uso de ferramentas digitais de interação em tempo real em sala de aula deve:

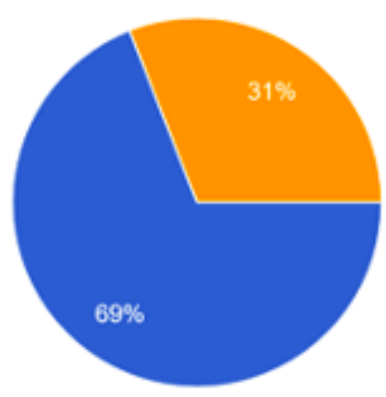

Ser ampliado, pois melhora a dinâmica da aula e facilita o aprendizado.

- Ser reduzido, pois compromete o tempo dedicado à resolução de exercícios e exposição de conteúdo.

Ser mantido igual: curto tempo de uso em aula mas deve permanecer. 
7. Na sua opinião, qual o maior benefício em se usar o Kahoot!?

$$
\begin{aligned}
& \text { Revisar conteúdos de aulas passadas. } \\
& \text { Identificar meus pontos fortes e pontos } \\
& \text { fracos no conteúdo da disciplina. } \\
& \text { Revelar como estou em relação aos } \\
& \text { meus colegas de turma em relaçăo a } \\
& \text { acertos e erros nos problemas. } \\
& \text { Servir como roteiro de estudo. } \\
& \text { Não vejo beneficio algum. }
\end{aligned}
$$

Fonte: acervo dos autores.

Alguns comentários sobre o aplicativo foram os seguintes:

"O Kahoot ajudou muito no desenvolvimento da matéria, focando sempre nos tópicos mais pertinentes $e$ estimulando uma competição saudável e descontraída."

"Iniciativas que fogem aos padrões de aula-lousa-slide da maioria das matérias da faculdade são sempre muito bem vindas! $O$ Kahoot é uma ótima ferramenta de aprendizado pois acertar ou errar não te condiciona um prejuizo na nota, apenas um acréscimo em aprendizado."

"Gostei da interação com o Kahoot. Acredito que se fosse disponibilizado e se desse algum prêmio aos que melhor performaram seria mais competitivo $e$ motivaria mais os estudos. Parabéns pela iniciativa e por nos ouvir."

"O Kahoot é bom para testar o conhecimento de forma leve sem a pressão das provas, só acho que o conteúdo deles poderia ter sido mais alinhado com o das provas. Mas, de forma geral é uma ótima ferramenta de
8. Em sua opinião, o uso do Kahoot! em sala de aula é melhor em sala de aula presencial ou sala de aula virtual?

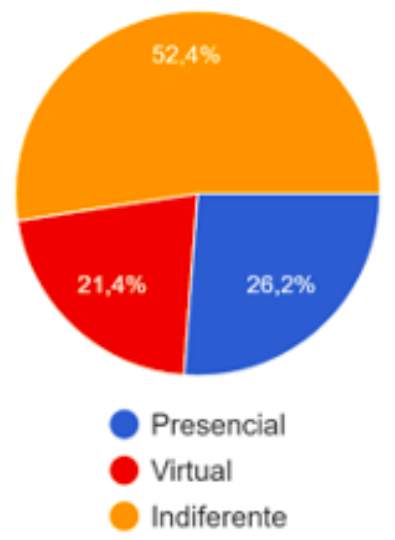

aprendizado que mais professores deveriam usar."

"O Kahoot faz um teste semanal...ele me possibilita de ver pontos fracos que eu não havia percebido e uma explicação do erro logo em seguida...também é boa para vermos o que erramos. Por fim, ele ajudava a prender minha atenção...vejo o Kahoot como uma maneira boa de melhorar o aprendizado."

"Muito bom o uso do KAHOOT, sensacional, mas disponibilize o material para os alunos, lembro que algumas questões eram realmente relevantes para a matéria, mas não consegui aprender direito porque não achei o material após a atividade."

A Figura 3 mostra o resultado da avaliação dos alunos sobre a Prova 1, realizada de forma síncrona. Os alunos receberam a prova por $e$ mail e, após a resolução, deveriam escaneá-la ou fotografá-la e fazer upload na sua pasta no Tidia-AE.

Já a Figura 4 mostra ainda o resultado de uma enquete sobre a percepção geral dos alunos sobre o curso. 
Figura 3 - Resultado da pesquisa sobre a Prova 1

1. Na sua opinião, o tempo dado para a prova 1 foi:

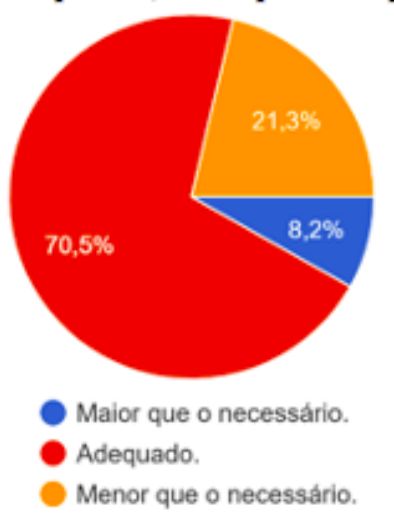

3. O nível de dificuldade da prova foi:

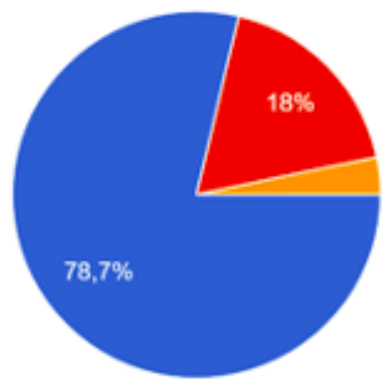

Igual ao dos exercicios e trabalhos.

Superior ao dos exercícios e trabalhos.

Inferior ao dos exercícios e trabalhos.
2. O conteúdo da prova foi:

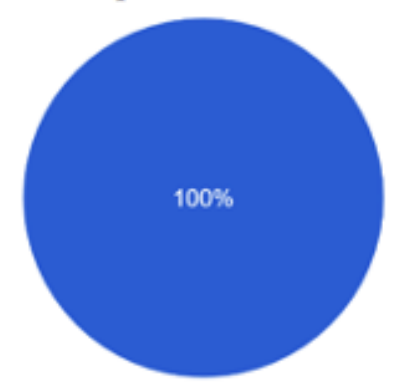

Coerente com o abordado nas aulas e exercicios.

Incoerente com o abordado nas aulas e exercicios.

4. Assinale a alternativa que melhor descreve sua experiência com a avaliação à distância feita em PQI3211:

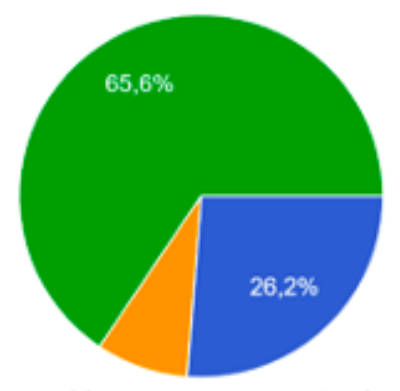

Tive problemas com a conexāo de internet e/ou computador, que foram facilmente sanados.

Tive problemas com a conexăo de internet elou computador, que nāo foram sanados.

- Tive problemas com a conexāo de internet e/ou computador, que foram sanados com dificuldade.

- Não tive nenhum problema de conexão e/ou computador.

5. Sua frequência estimada às aulas à distância é aproximadamente igual a:

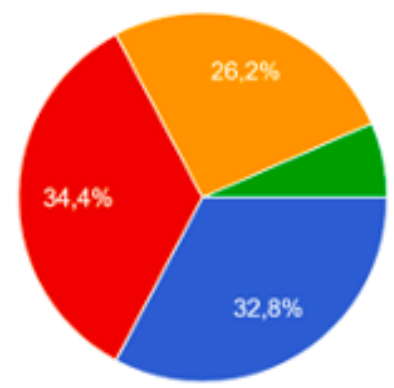

maior que $80 \%$

entre $50 \%$ e $80 \%$

inferior a $50 \%$

Não compareci a nenhuma aula à distância

Fonte: acervo dos autores. 
Figura 4 - Resultado da avaliação do curso

1. Os objetivos do curso foram claramente expostos no início da disciplina?

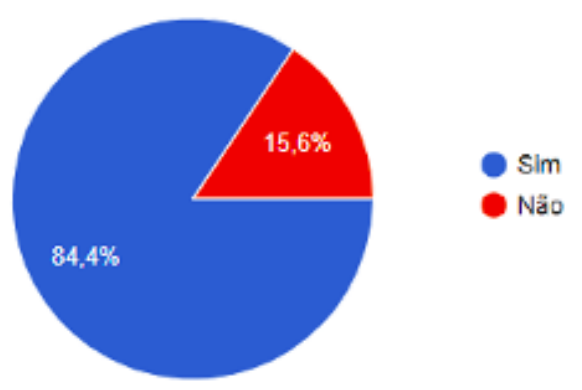

3. Em relação à didática do professor (transmissão do conteúdo com clareza e objetividade, definição de objetivos, exemplos, esclarecimento de dúvidas e motivação), você julgaria a didática apresentada em sala como:

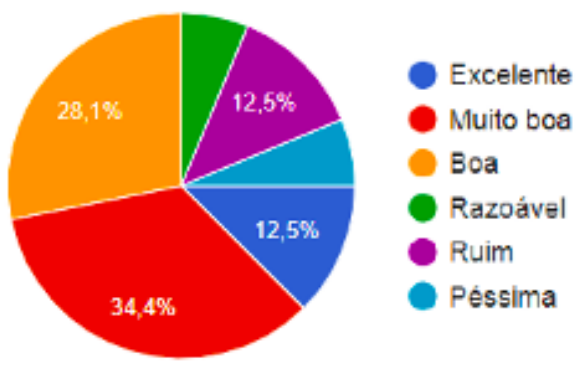

5. Em relação às avaliações (provas e listas), você acredita que:

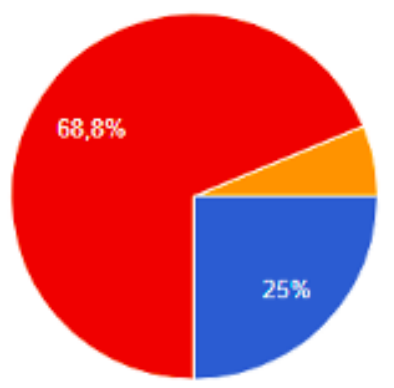

a) Săo muito mais dificeis que o material apresentado em aula.

b) Săo do mesmo nivel que o material apresentado em aula.

c) Säo menos exigentes que o material apresentado em aula.
2. Em relação à sua formação como engenheiro, você acredita que o conteúdo do curso será:

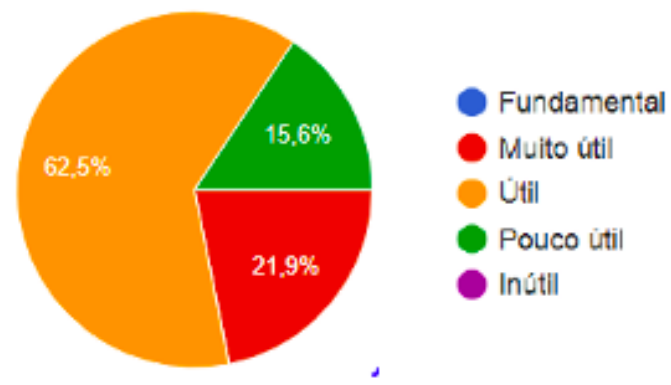

4. Em relação ao material didático (slides, listas de exercícios, uso e organização do quadro, vídeos etc), sua opinião sobre o material apresentado é:

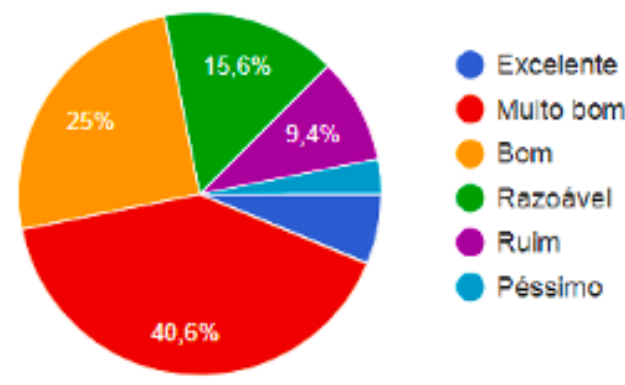

6. O nível de dedicação exigido pelo curso foi:

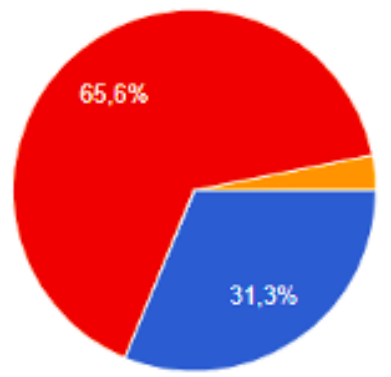

a) Superior as minhas expectativas.

b) Igual às minhas expectativas.

c) Inferior as minhas expectativas. 
7. Em relação aos conhecimentos prévios necessários para fazer o curso, sua opinião é de que:

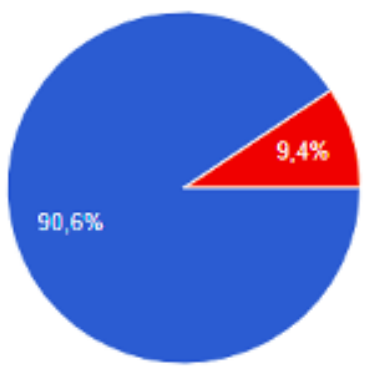
a) Os meus conhecimentos prévios foram suficientes para acompanhar o curso sem dificuldade.
b) Senti certa dificuldade por nã̃o ter conhecimentos prèvios ou não ter estudado uma quanticlade suficiente de um dos pré-requisitos.

9. O equilíbrio entre teoria e aplicação (exercícios) foi:

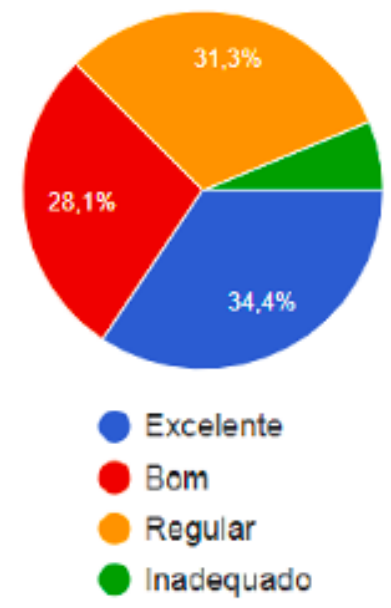

11. Qual o efeito que as aulas remotas devido à pandemia tiveram no seu aprendizado e desempenho no curso?
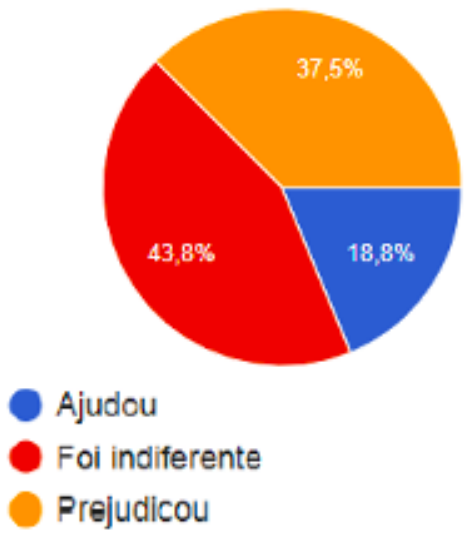

Fonte: acervo dos autores.
8. Caso tenha marcado a letra "b" para o item 7 , em qual desses temas você julga ter menos conhecimentos (assinale apenas uma alternativa):

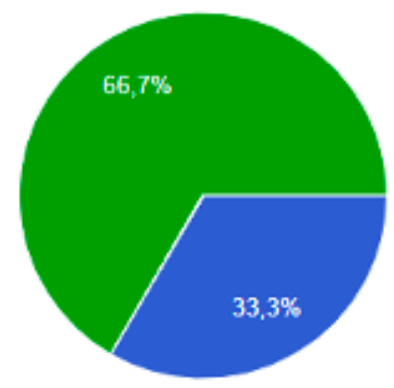

a) Termodinâmica.

b) Balanços de Massa e Energia.

c) Calculo.

d) Fenômenos de transporte.

10. A mudança do modo presencial para o modo remoto foi adequadamente conduzida, sem prejuizos para o curso.

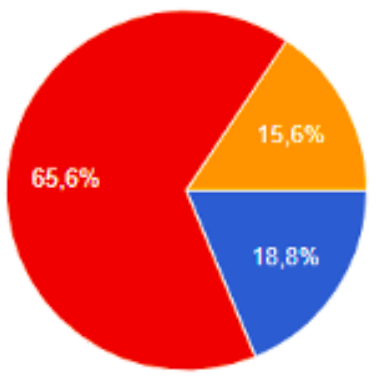

Concordo totalmente

Concordo parcialmente

Discordo totalmente

12. Como você avaliaria a disponibilidade do professor/monitor para esclarecimento de dúvidas e apoio na disciplina?

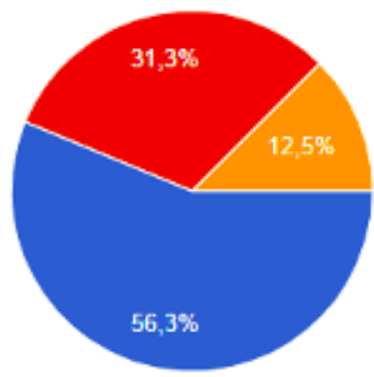

Muito disponivel.

Razoavelmente disponivel.

Indisponivel. 
Alguns comentários sobre a condução do curso foram os seguintes:

"A matéria estava sendo conduzida de forma bastante satisfatória antes da paralisação. Após esta, a disciplina continuou sendo bem conduzida, porém acho que a nova forma de avaliação acarretou um trabalho excessivo comparado ao que estava estipulado anteriormente devido ao relatório $e$ seminário."

"Para mim, as aulas foram muito bem dadas, principalmente a parte de resolução de exercícios. $O$ professor e a monitora sempre se mostraram dispostos a atender as dúvidas dos alunos. As avaliações foram coerentes com a teoria e o fato de ter entregáveis me ajudou a compreender a matéria como um todo de forma mais eficiente, no entanto, os prazos de entrega foram muito próximos."

"Achei que o seminário foi muito positivo porque tivemos contato com aplicações reais da matéria e aprendemos mais sobre indústrias químicas, vendo como a matéria pode ser útil, suas aplicações $e$ importância. Antes do seminário eu subestimava um pouco a importância da matéria, que depois eu vi ser muito útil e necessária na formação de um engenheiro de produção."

\section{CONCLUSÕES}

A implementação das metodologias e ferramentas descritas no trabalho nos permite traçar as seguintes conclusões gerais: i) alunos de Engenharia de Produção devem ser capacitados a avaliarem processos da indústria química, sob uma perspectiva econômica e ambiental; para isso, devem possuir um entendimento básico e conceitual das principais operações unitárias do setor, mas com um conhecimento sólido em balanços de massa e energia; ii) o aplicativo Kahoot! teve boa recepção entre os alunos, que o consideraram um elemento de motivação, dinâmica e revisão de conceitos em sala de aula; iii) a transição do modo presencial para o modo remoto foi feita mantendo-se o conteúdo e adaptando-se as ferramentas e avaliações, tendo sido ainda considerada pela maioria dos alunos como indiferente ou positiva para o aprendizado.

\section{AGRADECIMENTOS}

Os autores agradecem o apoio do Programa de Aperfeiçoamento de Ensino (PAE), através da concessão de bolsa de ensino. Os autores agradecem ao Prof. Dr. Roberto Guardani por disponibilizar uma videoaula sobre avaliação econômica de processos.

\section{REFERÊNCIAS}

ABIQUIM. Associação Brasileira da Indústria Química. O desempenho da indústria química brasileira. São Paulo, 2019.

ANDERSON, L. W. et al. A taxonomy for learning, teaching, and assessing: A revision of Bloom's Taxonomy of Educational Objectives. 1 ed. New York: Longman, 2001.

ATOMI. ActivePresenter 8, 2020. Disponível em:

<https://atomisystems.com/download/>. Acesso em: 10 abr. 2020.

BAWA, P. Using Kahoot to inspire. Journal of Educational Technology Systems, v. 47, n. 3, p. 373-390, 2018.

KAHOOT!. VERSVIK, M.; BRAND, J.; BROOKER, J. Norwegian University of Science and Technology (NTNU). Trondheim, Norway, 2012.

TELES DOS SANTOS, M.; VIANNA JR., A. S. Conhecimento como fonte de inovação no contexto do curso de engenharia química. XVII Encontro Brasileiro sobre o 
Ensino de Engenharia Química (XVII ENBEQ), 2018, São Paulo. Anais... XXII Congresso Brasileiro de Engenharia Química, 2018.

TIDIA-AE. Sobre o Ae, 2020. Disponível em: $<$ https://ae4.tidia- ae.usp.br/portal/pda/!gateway/tool/!gatew ay-210>. Acesso em: 15 ago. 2020.

WANG, A. I.; TAHIR, R. The effect of using Kahoot! for learning - A literature review. Computers \& Education, v. 149, p. 103818-103839, 2020.

\section{DADOS BIOGRÁFICOS DOS AUTORES}

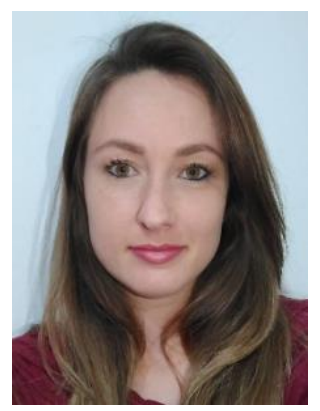

Priscila Hasse Palharim - Graduação em Engenharia Química pela Universidade Federal do Pampa (2017). Graduação sanduíche na University of California - San Diego (2013-2014), com bolsa CNPq. Mestrado em Engenharia Química pela Universidade de São Paulo (2019), com bolsa CNPq. Atualmente é Doutoranda do Programa de Pós-Graduação em Engenharia Química da Universidade de São Paulo, com bolsa CAPES.

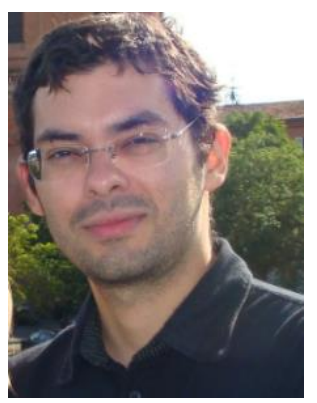

Moisés Teles dos Santos - Graduação em Engenharia Química pela Universidade Federal do Ceará (2004). Mestrado em Engenharia Química pela Universidade de São Paulo (2007). Doutorado em Engenharia de Processos e Meio-Ambiente pelo Institut National Polytechnique de Toulouse na França (2010). Trabalhou como engenheiro de pesquisa no LGC (Toulouse, França) desenvolvendo ferramentas computacionais para valorização da biomassa. Atualmente é Professor Doutor no Departamento de Engenharia Química da Escola Politécnica da USP. Foi Diretor Secretário e Diretor Tesoureiro da Associação Brasileira de Engenharia Química ABEQ (2015-2018) e Editor da Revista Brasileira de Engenharia Química. Tem trabalhos e publicações na área de desenvolvimento de softwares e novas técnicas de ensino-aprendizagem em engenharia. 